\title{
Evaluation of Gender Differences Based on Knowledge Adaptation in the Field of Gamification and Computer Science
}

\author{
https://doi.org/10.3991/ijet.v14i08.9847 \\ Andrija Bernik ( $\left.{ }^{\bowtie}\right)$, Damir Vusić, Marin Milković \\ University North, Varaždin, Croatia \\ andrija.bernik
}

\begin{abstract}
The authors' research activities connected information and communication technologies affecting teaching methods in higher education. A total of 201 respondents studying Programming 2 participated in this research. Two hypotheses were created, as well as a pre-test (ensuring that the initial condition of equality among the group members was met) and a post-test (measuring the shift of knowledge among the respondents of the same group). An analysis based on the t-test showed the presence of a statistically significant difference among the male respondents with regard to the test results. H1 hypothesis was accepted. No statistically significant difference was detected among the female respondents, so the $\mathrm{H} 2$ hypothesis was rejected. Our results showed that major difference have been found only in male population, which is interesting since female respondents tend to use LMS systems more often and since male respondents are more frequently in computer games activities.
\end{abstract}

Keywords-Computer Science, e-Learning, Gender differences, Gamification, University

\section{$1 \quad$ Introduction and Research Problem}

Teachers have been using games for educational purposes for many years, either in the form of specialised educational or commercial computer games. This is mainly due to the fact that they are entertaining and enable a dynamic approach to a particular topic or a subject of teaching. Digital games have become an everyday component of key importance for the socialisation process, in which games transcend pure entertainment and serve a broader purpose. Bicen and Wiggins state that technology and computer games have a significant impact on the traditional boundaries of education, which is evident through an industrial approach and a growing number of research studies on this topic. The results of their research confirm a positive attitude of respondents who use dynamic interactive systems focused on learning through computer simulations (economic, political, military, civil engineering, etc.) and their impact on behaviour, i.e. users play a specific scenario and monitor how their decisions affect the goals and results set out as learning outcomes. Commercial games or highly-specialised 
educational games especially developed for a target field can be used for this purpose. Both choices contribute to educational excellence [1-2].

Google and many independent research companies have recognised the notion and contemporary trend of gamification, among which Gartner and M2 research studies stand out [3-4]. In the 2013 Gartner report, gamification is positioned as a top technological innovation, whose development is being closely monitored (4-6).

The population born between 1995 and 2009, the so called 'Generation Z' is especially prone to this phenomenon [7]. These individuals are already, or have yet to become part of the higher education system and the business world. What makes them special is the fact that, while growing up, they were and still are constantly exposed to mobile and computer technologies and the influence of computer games. Their definition of entertainment is based on more dynamic systems, mostly relying on technological capabilities of the environment, which they expect and look for in future life situations as well. Upon entering the world of higher education, students become acquainted with LMS (Learning Management Systems). Peng Long and Tan, as stated in [8] made a study which included 1,192 students and interesting enough was that positive LMS usage likelihoods are associated with students who are younger, female, enrolled in Science and Technology majors, registered with LMS for five or more years. The most widely used of these systems is an open-source platform known as Moodle, which enables adaptation of a user interface and the use of elements of computer games depending on student characteristics and course requirements [9]. Communication and collaboration tools are used in an attempt to familiarise students with LMS, putting an emphasis on immediate feedback on the performance and a visual presentation of information they consider relevant.

Our research focuses on the influence of a gamified system on the respondents' gender. Tella and Mutula, as stated in [10], created experiment where 500 students were included (300 females and 200 males), where their results suggest that gender differences exist between female and male undergraduate students at the University of Botswana with regard to computer literacy. This findings could also lead to statistical difference in our research in programming field, since differences exist in the respondents' computer usage and software application [10].

Added to above, it is well known that the male population is more inclined to computer games. Due to the fact that male respondents spend more time playing computer games, we would like to carry out an empirical test involving an LMS complemented by computer game elements. Our aim is to examine how a gamified system affects the respondents' gender with regard to knowledge improvement. We would like to note here that our research will not focus on a direct comparison of results of the female and male respondents, but will provide an overview in this respect.

H1. Regardless of the respondents' prior knowledge, male students from the experimental group in the main research will achieve a statistically more significant result compared to the male students from the control group.

H2. Regardless of the respondents' prior knowledge, female students from the experimental group in the main research will achieve a statistically more significant result compared to the female students from the control group. 


\section{Research Methodology}

\subsection{Theoretical research}

We will analyse the field of e-learning, computer games, gamification and the influence on learning motivation. General scientific methods such as observation, description, comparison, synthesis and content analysis will be used, in order to analyse some of the existing Moodle courses used for teaching IT related subjects with the aim of creating a conceptual model and achieving the first and second research objectives.

\subsection{Empirical research}

For the purpose of this paper, empirical research was carried out in several phases. In the testing phase, pre-research was carried out on the second-year students of the University North. This research phase primarily focused on testing the gamified system for the purpose of removing technical and logical errors. Fifty-five respondents, students of the '3D modelling' elective course, volunteered for the pre-research. The conclusions made on the basis of the pre-research were analysed once more and introduced into the main research [11]. The main research was carried out at the Faculty of Organization and Informatics in Varaždin. A total of 201 respondents participated in the main research. The respondents were students of the 'Programming 2' course who participated in the research on a voluntary basis. Programming course was selected cause of STEM field and cause of several cases which states that the most the most active research areas, in terms of IT and Computer Science, include control engineering, computer-assisted instruction (CAI), programming techniques, asynchronous transfer mode, image processing, software engineering, etc [12].

In order to confirm the hypotheses $\mathrm{H} 1$ and $\mathrm{H} 2$, several steps were designed as described below.

An analysis of technical and scientific literature was carried out in the preliminary research phase in order to achieve the first and the second objective of this research paper. Key elements of mechanics, dynamic and aesthetics were identified. Technical requirements for designing and carrying out a research study and the layout of a standard Moodle e-course were examined.

- In the first research phase a gamified Moodle e-course was designed for the experimental group and control group. The teaching material was adapted for this research, without affecting its content. The first phase was concluded by an analysis of the stability and the correct functioning of both systems.

- In the second phase, the respondents were familiarised with the research method and purpose. Each group of students participating in the experiment was grouped in accordance with the time schedule of course exercises. At this point it was not known whether a group of respondents was control or experimental.

- In the third phase on the basis of the pre-test score, we concluded that there was no statistically significant difference between the groups which might emerge in the 
experimental e-course. The groups were divided into experimental and control with regards to the average score.

- The main research pre-test contained 30 questions (25 questions with 4 suggested answers and 5 open-ended questions). The questions covered general programming terms, such as questions about $\mathrm{C}++$ commands, variables, logical operators, etc.

- In the final phase, the students following both e-courses studied the teaching material only through the e-course. They used the system for a minimum of 14 days, upon which a post-test was performed. A statistically significant difference was calculated with the t-test method. We examined how much the result had changed and made a conclusion about the confirmation of the hypotheses. The post-test questions covered specific terms from the field of programming, such as the questions about calculating a subordinate stack node, stack operations, NULL pointers, etc.

The respondents voluntarily participated in the research activities and had an active role in the validation of the conceptual model. The hypotheses were tested and validated in line with the previously agreed rules that had to be observed with each group of respondents in each of the selected courses.

\section{Introducing Motivating Elements of Computer Games into the Education System}

Landers and Callan examined the techniques for motivating students by developing an educational social network within the period of one semester. A total of 385 students who had accepted an e-mail invitation participated in the research study. Along with the teaching material, the authors' e-learning system offered the students the possibility to set their profile pictures and post public messages about their achievements.

Their system supported asynchronous communication and the use of badges and certificates [14]. Furthermore, Landers and Callan point out that internal (university) social networks can positively affect student motivation. Students should be openly rewarded for their achievements and this information should be shared on social networks; the more valuable and concrete a reward is to the student, the more motivated they will be. The reward should commensurate with the level of a desired activity or knowledge assessment. The level should be increased gradually. The activity and knowledge assessment feedback should be immediate. Attention should be paid to the visual aspect and ambience where teaching takes place.

According to Muntean, students can be motivated by a feeling of pleasure, pain, fear, hope and the social status (being either accepted or rejected). If students are highly motivated but lack a certain degree of ability, there will be no change in behaviour and/or the learning process will not be efficient [13]. Muntean goes on to say that triggers, i.e. the elements suggesting the student to carry out a certain activity at a certain moment should also be included. Student activities can be triggered by a simple signalling or by a narrator reacting in the crucial moment. 
In order to achieve this, the student should know how to draw conclusions, identify and learn new things on the basis of presented information. The activation of all of the above-mentioned three elements induces the so-called state of flow. Muntean points out to a problem with e-courses when conveying a stimulus or an emotion present in the teacher-student interaction. Due to this reason, e-learning systems should be expanded by technological solutions stimulating student motivation and their participation in teaching activities.

In the following section we will list the elements of game mechanics that can be used to stimulate intrinsic motivation (Table 1).

Table 1. The link between Game Mechanics and Intrinsic Motivation (according to $[1,13]$

\begin{tabular}{|c|c|c|c|c|c|c|}
\hline & Awards & Status & Achievement & $\begin{array}{c}\text { Self- } \\
\text { expression }\end{array}$ & Competition & Altruism \\
\hline Points & $\checkmark$ & o & o & & 0 & 0 \\
\hline Levels & & $\checkmark$ & 0 & & 0 & \\
\hline Challenges & 0 & 0 & $\checkmark$ & 0 & 0 & 0 \\
\hline $\begin{array}{c}\text { Virtual } \\
\text { Currency }\end{array}$ & 0 & 0 & 0 & $\checkmark$ & 0 & \\
\hline Top List & & 0 & 0 & & $\checkmark$ & 0 \\
\hline Gifts & & 0 & 0 & & 0 & $\checkmark$ \\
\hline
\end{tabular}

Muntean argues that correct gamification of e-learning should involve gradual disclosure of the content and a stronger focus on repetition, exercises and knowledge assessment. Students should be awarded points for correct answers [13].

Gamification of e-learning aims to raise student motivation and engagement in learning activities available within a gamified system. This leads us to conclude that if students use the system for a longer period, it is more likely that they will achieve better knowledge assessment results.

Table 2. Research Papers in which Gamified Systems Were Used in Higher Education [15-19]

\begin{tabular}{|l|c|c|l|}
\hline \multicolumn{1}{|c|}{ Author(s), Year } & $\begin{array}{c}\text { Duration of the } \\
\text { Research }\end{array}$ & No. of students & \multicolumn{1}{|c|}{ Computer Game Elements } \\
\hline $\begin{array}{l}\text { Landers and Callan } \\
\text { (2011) }\end{array}$ & 1 semester & 385 & $\begin{array}{l}\text { Avatar, social networks, badges, } \\
\text { certificates, forum }\end{array}$ \\
\hline $\begin{array}{l}\text { Jayasinghe and Dharmaratne } \\
(2013)\end{array}$ & 60 minutes & 60 & Points, feedback \\
\hline de Marcos et al (2014) & 1 semester & 371 & $\begin{array}{l}\text { Badges, social networks, forum, } \\
\text { follow and like, chat }\end{array}$ \\
\hline $\begin{array}{l}\text { Iosup and Epema } \\
(2014)\end{array}$ & 4 semesters & 450 & $\begin{array}{l}\text { Points, levels, leader boards, } \\
\text { badges, explanations for } \\
\text { beginners, social loops and } \\
\text { gradual content disclosure }\end{array}$ \\
\hline $\begin{array}{l}\text { Laskowski and Badurowicz } \\
(2014)\end{array}$ & 1 semester & 62 & Points, badges, scoreboard \\
\hline $\begin{array}{l}\text { Schreuders and Butterfield } \\
(2016)\end{array}$ & 4 semesters & 32 & Points, feedback \\
\hline
\end{tabular}

As a consequence, they will acquire knowledge faster and achieve better results. The teacher, administrator or e-course designer should include some of the following game elements into traditional e-learning systems: avatars, notifications, chapters (teaching units), and levels (teaching levels). 
In conclusion, after acquiring the content of certain learning units, students will advance to higher learning levels where they will acquire new knowledge by tackling more difficult exercises, while the learning material will be more abstract. Table 2. lists some of the researchers who studied the influence of gamification on students within the higher education system, with indicated research duration and the number of respondents. It also lists the game elements used by the researchers in order to design their respective gamified systems.

It can be concluded from the above-mentioned studies that the visual aspect and ambience where teaching material is presented and studied should be taken into consideration, and that gamified systems could include avatars, notifications, chapters and learning levels. The above mechanisms will be considered in the process of selecting the game elements that will be introduced into the gamified system of the main research.

\section{$4 \quad$ Research Results}

In order to confirm the $\mathrm{H} 1$ and $\mathrm{H} 2$ hypotheses, a post-test was conducted within the main research in order to obtain a list of respondents meeting the requirements for research participation, which enabled a t-test analysis of the results aimed at confirming or rejecting the $\mathrm{H} 1$ and $\mathrm{H} 2$ hypotheses. The respondents from the control and the experimental group were grouped according to gender, and an analysis of the male respondents of the control and experimental group, as well as an analysis of the female respondents from the control and the experimental group were carried out. Presented below are the results of comparison of the male respondents and that of the female respondents from the experimental and the control group. The post-test comprised 30 questions, with a total of $\mathbf{2 0 1}$ respondents.

Table 3 shows the comparison of the male and female respondents from the experimental and the control group. Also it shows a statistically significant difference among the male respondents as regards points from the post-test. The experimental group of respondents achieved a better result in the post-test than the control group of respondents by $\mathbf{1 8 . 8 8 \%}$.

Table 3. The results of comparison of the male respondents and that of the female respondents from the experimental and the control group

\begin{tabular}{|l|c|c|c|c|}
\hline & \multicolumn{2}{|c|}{ Overall Results of Male Students } & \multicolumn{2}{c|}{ Overall Results of Female Students } \\
\hline Group of Students & Exp. group [N=80] & $\begin{array}{c}\text { Control Group } \\
{[\mathbf{N}=77]}\end{array}$ & Exp. group [N=19] & $\begin{array}{c}\text { Control Group } \\
{[\mathbf{N}=\mathbf{2 5}]}\end{array}$ \\
\hline Average score & $\mathbf{1 3 . 3 5}$ & 11.23 & 13.95 & 11.60 \\
\hline Std. dev. & $\mathbf{5 . 6 9}$ & 5.04 & 6.59 & 4.31 \\
\hline $\mathrm{t} / \mathrm{p}$ value & \multicolumn{2}{|r|}{$2.462 / \mathbf{0 . 0 1 4 9}$} & \multicolumn{2}{|c|}{$1.427 / \mathbf{0 . 1 6 1 0}$} \\
\hline
\end{tabular}

Given the post-test score within the main research, a conclusion is drawn that there is a statistically significant difference between the above groups, based on the t-test analysis, thus confirming the $\mathrm{H} 1$ hypothesis of this research.

In the case of the $\mathrm{H} 2$ hypothesis, where the female respondents from the experimental group were compared to the female respondents from the control group, a conclusion is drawn that there is no statistically significant difference between these groups, regardless of the better overall result of the experimental group of respondents by $\mathbf{2 0 . 2 6 \%}$ compared to the control group of respondents; the $\mathrm{H} 2$ hypothesis of this 
research is, therefore, rejected. Such a result might be due to a small number of respondents.

\section{$5 \quad$ Conclusion and Discussion}

In order to confirm the hypotheses, a post-test was conducted within the main research, based on which a list of respondents meeting the requirements to participate in the research was obtained, and which enabled an analysis of the results in terms of achieved points for the purpose of confirming or rejecting the $\mathrm{H} 1$ and $\mathrm{H} 2$ hypotheses set out in the research. The final phase of the empirical research, set out in the first section, is based on the calculation of the statistical indicators, such as standard deviation (SD), t-test, central tendency measures, descriptive statistics, and other statistical indicators based on which a valid conclusion can be made on the statistical difference between the results achieved by the respondents from both groups. The total number of questions in the post-test was 30, while the total number of respondents participating in the post-test was 201. After analysing the results of the comparison of the male respondents from the experimental group $(\mathrm{N}=80)$ with the male respondents from the control group ( $\mathrm{N}=77)$, shown in Table 3, it is evident that there is a statistically significant difference among the male respondents in the post-test points. The calculated $t$ value is 2.462 , while the $\mathrm{p}$ value is 0.0149 . The experimental group of respondents $(\mathrm{N}=80)$ achieved a better result in the post-test than the control group of respondents $(\mathrm{N}=77)$ by $18.88 \%$; thus, a conclusion is drawn that there is a statistically significant difference between these groups in favour of the experimental group of respondents. As a result, the $\mathbf{H 1}$ hypothesis of this research is accepted.

In line with the above, an analysis of the results achieved by the female respondents from the experimental group $(\mathrm{N}=19)$ and the female respondents from the control group $(\mathrm{N}=25)$ was carried out. As regards the analysis of the female respondents, based on the t-test, it should be pointed out that there is no statistically significant difference between the experimental and the control group, despite the higher average value of points by $\mathbf{2 0 . 2 6 \%}$ recorded in the experimental group of respondents. Based on the above, a conclusion is drawn that there is no statistically significant difference between these groups, regardless of the better average result of the experimental group of respondents; thus the $\mathbf{H} \mathbf{2}$ hypothesis of this research is rejected. Such a result might be due to a small number of respondents.

The contribution of this research is based on creating and testing a gamified e-course in the Moodle environment in the field of teaching information science subjects. Two separate Moodle e-courses were created, comprising the teaching content of information science (programming). The systems were tested and their influence on the attendants measured by analysing the average results through a post-test.

Given the initial requirements met by all of the respondents, statistically significant differences were identified, with the possibility of error of $1 \%$ or $5 \%$, between the control and the experimental group of male respondents, on the basis of which the H1 hypothesis was accepted and the $\mathrm{H} 2$ hypothesis was rejected. 
The research results are interesting because no statistically significant difference was expected in either of the cases. It is interesting to find out that in the research from other authors such as [20], there isn't any statistical significant difference between gender, but in our findings that is not the case. According to [21], male gender is more represented than female among the gamers, with the ratio being $60 \%: 40 \%$. Does the reason behind the results obtained in this research lie behind the fact that male respondents spend more time playing computer games? Also interesting is the research carried out by the organisation Overflow, which included 101,592 programmers from altogether 183 countries. The majority of respondents were from Europe $(39,001)$, North America $(25,016)$ and Asia $(24,700)$. The questionnaire was completely filled out by $66,441(66.4 \%)$ respondents. The result comes as a bit of a shock: among the programmers were as many as $92.7 \%$ male respondents, and only $6.8 \%$ female ones, while $0.5 \%$ did not state their gender. Perhaps the very field of programming affected the result. Would the result have been different if the field in question had been social sciences? These questions are considered highly important by the authors and will be addressed in their future research works [22].

\section{References}

[1] Bicen, H., \& Kocakoyun, S. (2018). Perceptions of Students for Gamification Approach: Kahoot as a Case Study. International Journal of Emerging Technologies in Learning (iJET), 13(02), 72-93. https://doi.org/10.3991/ijet.v13i02.7467

[2] Turan, Z., Avinc, Z., Kara, K., \& Goktas, Y. (2016). Gamification and education: Achievements, cognitive loads, and views of students. International Journal of Emerging Technologies in Learning (iJET), 11(07), 64-69. https://doi.org/10.3991/ijet.v11i07.5455

[3] Rivera, J., and Van der Meulen, R. 2013. Gartner's 2013 hype cycle for emerging Technologies maps out evolving relationship between humans and machines. Gartner.

[4] Webb, E. N. 2013. Gamification in enterprise: Gartner Hype Cycles 2013. Gartner Inc. 2013. Available at: gartner.com/newsroom /id/2575515.

[5] LeHong, H., and Fenn, J. 2012. Key trends to watch in gartner 2012 emerging technologies hype cycle. Gartner Inc. Available at: www.forbes.com/sites/ gartnergroup/2012/09/18/keytrends-to-watch-in-gartner-2012-emerging-technologies-hype-cycle-2.

[6] Bruke, B. 2013. Gartner says get gamification working for you, Gartner Report, Report ID: G00245563 Gartner Inc. 2013. Available at: www.thisiswhatgoodlookslike.com/2013/03/24/gartner-says-get-gamification-working-for-you/.

[7] Veluchamy, R., Agarwal, K. K., Loganathan, M., and Krishnan, A. R. 2016. Perception on the Role of Teachers in Managing Talents of Generation Z Students An Ideal Teacher. Indian Journal of Science and Technology, 9(36). https://doi.org/10.17485/ijst/2016/v9i36/102604

[8] Peng Long, Ng and Andrew KG Tan. 2017. Determinants of e-resource usage by open distance learning university students. Malaysian Journal of Library and Information Science 22, no. 1 (2017): 29-44.

[9] Souza-Concilio, I. A. and Pacheco, B. A. 2013. Games and Learning Management Systems: A Discussion about Motivational Design and Emotional Engagement. Proceedings of the SBGames, Brazil, 38-45.

[10] Tella, Adeyinka and Stephen M. Mutula. 2008. Gender differences in computer literacy among undergraduate students at the University of Botswana: implications for library use. Malaysian Journal of Library and Information Science 13, no. 1 (2008): 59-76. 
[11] Bernik, A., Bubas, G., and Radosevic, D. 2015. A Pilot Study of the Influence of Gamification on the Effectiveness of an e-Learning Course. In Central European Conference on Information and Intelligent Systems, 73-79. Faculty of Organization and Informatics Varazdin.

[12] Yinian, Gu and A. N. Zainab. 2001 Publication productivity of Malaysian researchers in the field of Computer Science and Information Technology. Malaysian Journal of Library and Information Science 6, no. 1 (2001): 1-23.

[13] Muntean, C. I. 2011. Raising engagement in e-learning through gamification. In Proc. 6th International Conference on Virtual Learning ICVL (Vol. 1)., 323-329.

[14] Landers, R. N., and Callan, R. C. 2011. Casual social games as serious games: The psychology of gamification in undergraduate education and employee training. In Serious games and edutainment applications, 399-423. Springer, London.

[15] Jayasinghe, U., and Dharmaratne, A. 2013. Game based learning vs. gamification from the higher education students' perspective. In Teaching, Assessment and Learning for Engineering (TALE), 2013 IEEE International Conference on, 683-688. IEEE.

[16] De-Marcos, L., Domínguez, A., Saenz-de-Navarrete, J., and Pagés, C. 2014. An empirical study comparing gamification and social networking on e-learning. Computers and Education, 75, 82-91. https://doi.org/10.1016/j.compedu.2014.01.012

[17] Iosup, A., and Epema, D. 2014. An experience report on using gamification in technical higher education. In Proceedings of the 45th ACM technical symposium on Computer science education, 27-32. ACM. https://doi.org/10.1145/2538862.2538899

[18] Laskowski, M., and Badurowicz, M. 2014. Gamification in higher education: a case study. In Management, Knowledge and Learning (MakeLearn) International Conference 2014, 971-975.

[19] Schreuders, Z. C., and Butterfield, E. M. 2016. Gamification for teaching and learning computer security in higher education. In 2016 USENIX Workshop on Advances in Security Education (ASE 16). USENIX Association.

[20] Batsila, M., Tsihouridis, C., \& Tsihouridis, A. (2017). "All for One and One for All"Creating a Mobile Learning Net for ESP Students' Needs. International Journal of Emerging Technologies in Learning (iJET), 12(04), 17-38. https://doi.org/10.3991/ijet.v12i04.6428

[21] Paaßen, B., Morgenroth, T., and Stratemeyer, M. 2017. What is a true gamer? The male gamer stereotype and the marginalization of women in video game culture. Sex Roles, 76(78), 421-435. https://doi.org/10.1007/s11199-016-0678-y

[22] Overflow, S. 2018. Developer Survey Results 2018. Available at: http://insights.stackoverflow.com/survey/2018/.

\section{$7 \quad$ Authors}

Andrija Bernik is a lecturer at the University North, Croatia.

Damir Vusić is an associate professor at the University North, Croatia.

Marin Milković is a full professor at the University North, Croatia.

Article submitted 2018-11-12. Resubmitted 2018-12-31. Final acceptance 2019-01-07. Final version published as submitted by the authors. 